\title{
Ensino de Bioética Dentro de um Programa de Residência Médica em Geriatria - Experiência de Seis Anos de Discussão de Conflitos Bioéticos
}

\author{
Hojaij, Naira Hossepian Salles de Lima; Oliveira, Reinaldo Ayer de; Rangel, Luis \\ Fernando; Cohen, Claudio; Filho, Wilson Jacob \\ Serviço de Geriatria do Hospital das Clínicas da Faculdade de Medicina da Universidade de São \\ Paulo _ hohojaij@uol.com.br
}

Introdução: o processo de envelhecimento populacional, observado a partir da segunda metade do século XX em nosso país, trouxe um aumento expressivo das doenças crônico-degenerativas. o cuidado a esses idosos, em geral portadores de multimorbidade e, por vezes, frágeis do ponto de vista funcional e/ou próximos da finitude humana, traz ao dia-a-dia do geriatra dúvidas e conflitos de ordem bioética, que podem influenciar de maneira significativa as tomadas de decisão clínicas. Objetivo: Diante da necessidade de discussão orientada de questões que transcendem a prática clínica, iniciamos em 2008 reuniões de discussão de casos clínicos com demanda bioética, com o objetivo de levar diretrizes e aprendizado em bioética aos residentes de Geriatria de nosso serviço. Métodos: As reuniões são de periodicidade trimestral, duração de 90 minutos, na qual participam todos os membros do serviço de Geriatria de nosso hospitalescola, além de convidados do departamento de Medicina Legal, Ética Médica e Medicina Social e do Trabalho de nossa Faculdade de Medicina, ou de estudiosos de outras áreas no assunto. Os conflitos bioéticos são trazidos pelos residentes de primeiro e segundo anos, a partir de casos atendidos em todos os estágios dentro do programa de residência médica em Geriatria. Inicialmente, os aspectos clínicos são extensivamente discutidos, a seguir, após a discussão ampla de opiniões sobre as demandas bioéticas, baseadas em experiências e norteadas pelo nosso atual código de Ética Médica e outros códigos de condutas, é sugerida aos médicos residentes a tomada de decisão que mais se aproxima do bom senso. Resultados: do início de 2008 até o final de 2013, foram realizadas 24 reuniões clínico-bioéticas em nosso serviço. Os assuntos abordados nesses seis anos de experiência foram: sigilo médico; responsabilidade médica e institucional; cuidados paliativos em demência avançada; cuidados avançados em demência ; direito de acesso ao prontuário médico; comunicação da relações médicas e comunicação de más notícias; finitude; limite de ações médicas; conflitos interdisciplinares; retirada de medidas de prolongamento de vida em UTI; ordem de não reanimar; relação médicopaciente; termos de consentimento e de responsabilidade; direitos e deveres do paciente e da instituição; sedação paliativa em situações não usuais; diretivas antecipadas de vontade; etarismo ou discriminação ao idoso; alocação de recursos. Conclusões: Diante da crescente demanda de aspectos bioéticos dentro dos cuidados ao indivíduo idoso, que incluem também os cuidados no período de proximidade à morte, entendemos que houve um fortalecimento do aprendizado ético e humanístico dos médicos residentes de Geriatria, através de um modelo de discussão orientada de aspectos clínicos e bioéticos de casos vivenciados em sua prática médica.

Hojaij, Naira Hossepian Salles de Lima; Oliveira, Reinaldo Ayer de; Rangel, Luis Fernando; Cohen, Claudio; Filho, Wilson Jacob. Ensino de Bioética Dentro de um Programa de Residência Médica em Geriatria - Experiência de Seis Anos de Discussão de Conflitos Bioéticos.. In: Anais do Congresso Internacional de Humanidades \& Humanização em Saúde [= Blucher Medical Proceedings, num.2, vol.1]. São Paulo: Editora Blucher, 2014. ISSN 2357-7282

DOI 10.5151/medpro-cihhs-10557 